\title{
Physiological Measurements of Luminal Stirring in the Dog and Human Small Bowel
}

Michael D. Levitt, Julie K. Furne, Alessandra Strocchi, Beth W. Anderson, and David G. Levitt

Research Service, Veterans Administration Medical Center, and Departments of Medicine, Nutrition, and Physiology, University of Minnesota, Minneapolis, Minnesota 55417

\begin{abstract}
The resistance to absorption resulting from poor stirring of luminal contents $\left(\boldsymbol{R}_{\mathrm{Lum}}\right)$ is considered to be equivalent to an unstirred layer of greater than $600 \mu \mathrm{m}$ in the human small intestine. We measured $\boldsymbol{R}_{\mathrm{Lum}}$ in the jejunum of conscious dogs by assessing the absorption rate of two rapidly absorbed probes, glucose, and [ ${ }^{14} \mathrm{C}$ ] warfarin. When $\boldsymbol{R}_{\mathrm{Lum}}$ was expressed as an unstirred layer, the maximal thickness of the unstirred layer (assuming negligible epithelial cell resistance) was only $\sim 35$ and $50 \mu \mathrm{m}$ for perfusion rates of 26 and $5 \mathrm{ml} / \mathrm{min}$, respectively. Maximal unstirred layer thickness for the human jejunum, calculated from previous studies of glucose absorption, yielded a mean value of only $40 \mu \mathrm{m}$ (range: 23 to $65 \mu \mathrm{m}$ ). Since epithelial resistance appears to be negligible during absorption of low concentrations of glucose, the maximal unstirred layer of $40 \mu \mathrm{m}$ should be close to the true value for glucose in the human small intestine. We conclude that the unstirred layer for rapidly absorbed compounds in dogs and man are less than one-tenth of previously reported values, but this layer still may remain the rate limiting step in absorption of rapidly transported compounds. (J. Clin. Invest. 1990. 86:1540-1547.) Key words: luminal stirring • jejunum • glucose - absorption
\end{abstract}

\section{Introduction}

The absorption rate of a solute from the gut depends upon the concentration of the solute at the brush border and the subsequent rate of transport of the compound by the mucosa. The delivery of solute to the brush border is a function of the efficiency of luminal stirring. A wide variety of in vitro (1-8) and in vivo $(3,9-18)$ studies have suggested that luminal stirring is relatively poor and large aqueous diffusion barriers build up adjacent to the mucosa. Expressed as a uniform thickness of unstirred water, this preepithelial diffusion barrier in man is thought to produce a resistance equivalent to an unstirred layer of greater than $600 \mu \mathrm{m}(9,10,12)$. Such a relatively enormous diffusion barrier would drastically reduce

Address reprint requests to Dr. Michael Levitt, VA Medical Center, One Veterans Drive, Minneapolis, MN 55417.

Received for publication 29 November 1988 and in revised form 6 July 1990.

1. Abbreviations used in this paper: PSP, phenolsulfonphthalein.

J. Clin. Invest.

(C) The American Society for Clinical Investigation, Inc. $0021-9738 / 90 / 11 / 1540 / 08 \quad \$ 2.00$

Volume 86, November 1990, 1540-1547 the absorption of any compound that is rapidly transported across the mucosa.

Most studies of resistance due to poor luminal stirring in animals have been carried out in vitro or in laparotomized animal preparations where limited intestinal motility is likely to have reduced luminal stirring. In a recent study (19), more physiological measurements in the nonlaparotomized rat showed the preepithelial resistance to be equivalent to an unstirred layer of only $100 \mu \mathrm{m}$, a value much lower than previously reported for any species. The initial goal of the present study was to obtain physiological measurements of unstirred layer resistance in an animal whose small bowel has dimensions and motility more comparable to that of man. To this end we perfused the intestine of conscious dogs via a Thomas cannula and calculated unstirred layer resistance from the absorption rate of rapidly transported probes. These results led us to calculate in similar fashion unstirred layer resistance in man from previously published studies of glucose absorption. We conclude that luminal resistance to glucose absorption in humans is less than one-tenth the conventionally cited value for unstirred layer thickness.

\section{Methods}

Three, 25-30-kg adult, mongrel dogs were trained to lie quietly on a surgical table. Upon completion of training, a Thomas cannula was implanted in the duodenum or proximal jejunum within $15 \mathrm{~cm}$ of the ligament of Treitz. Postoperative therapy consisted of butorphanol (4 $\mathrm{mg} / \mathrm{kg}$ daily i.m.) for $2 \mathrm{~d}$, Durapen (Vedco, Overland Park, Kansas, $900,000 \mathrm{U} / \mathrm{kg}$ i.m. daily $)$ and gentamicin $(80 \mathrm{mg} / \mathrm{kg}$ i.m. daily $)$ for $3 \mathrm{~d}$.

After a 2-wk recovery period, perfusion studies were performed. The perfusion apparatus consisted of four tubes. The infusion and aspiration port were separated by a distance of $20 \mathrm{~cm}$ and balloon tipped cannulas were located just proximal to the infusion site and distal to the aspiration site. The infusion and aspiration tubes consisted of PE 160 and PE 240 tubing, respectively, and PE 50 tubing was used for the balloon cannulas. A mercury bag was attached to the distal end of the assembly to facilitate passage. After an $18 \mathrm{~h}$ fast, the perfusion apparatus was inserted into the intestine via the cannula. When the tube had passed $\sim 30 \mathrm{~cm}$, the upper and lower balloons were distended with 5 to $10 \mathrm{ml}$ of saline. The $20-\mathrm{cm}$ jejunal segment was then perfused with isotonic saline containing $\left[{ }^{3} \mathrm{H}\right]$ polyethylene glycol (PEG) $(100,000 \mathrm{dpm} / \mathrm{ml}$ and $0.1 \mathrm{~g} / \mathrm{dl})$, glucose $(100 \mathrm{mg} / \mathrm{dl})$, and trace quantities of $\left[{ }^{14} \mathrm{C}\right]$ warfarin $(40,000 \mathrm{dpm} / \mathrm{ml})$. The solution was infused with a rotary pump (Masterflex; Barnant Co., Barrington, IL) at a rate of 5 or $26 \mathrm{ml} / \mathrm{min}$ and the segment was drained by siphonage. After equilibration, multiple samples of the perfusate were obtained for analysis. Using standard constant perfusion equations, absorption of glucose and $\left[{ }^{14} \mathrm{C}\right]$ warfarin were calculated using $\left[{ }^{3} \mathrm{H}\right] \mathrm{PEG}$ as a dilutional marker.

To measure luminal volume of the segment, at the end of the study, the infusate was switched to isotonic saline containing no $\left[{ }^{3} \mathrm{H}\right] \mathrm{PEG}$ 
and all $\left[{ }^{3} \mathrm{H}\right]$ PEG was flushed from the segment. Segment volume was determined from the total $\left[{ }^{3} \mathrm{H}\right] \mathrm{PEG}$ recovered, divided by the mean $\left[{ }^{3} \mathrm{H}\right] \mathrm{PEG}$ concentration of the aspirates (before switching to the [ $\left.{ }^{3} \mathrm{H}\right]$ PEG-free solution). In several studies, segment volume also was measured by a bolus injection of $0.1 \mathrm{ml}$ of phenolsulfonphthalein (PSP) ${ }^{1}$ with analysis of PSP outflow concentration using the StewartHamilton formula (20). Results were comparable to the above described method.

Analysis of $\left[{ }^{3} \mathrm{H}\right] \mathrm{PEG}$ and $\left[{ }^{14} \mathrm{C}\right]$ warfarin was by liquid scintillation counting, glucose analysis was by a glucose oxidase technique, and PSP by spectrophotometry.

Calculations of luminal resistance and unstirred layer thickness. The methods employed to calculate resistances to absorption are identical to those used in previous publications $(13,19)$. The absorption rates of glucose or $\left[{ }^{14} \mathrm{C}\right]$ warfarin were normalized for logarithmic mean luminal concentration (19) to yield a value comparable to clearance:

clearance $=($ fraction absorbed $) \cdot($ infusion rate $) \cdot(c / \bar{c})$,

where $c / \bar{c}$ represents the ratio of initial to logarithmic mean concentration of the probe. Clearance was then normalized for area of the aqueous diffusion barrier yielding units of $\mathrm{cm} / \mathrm{min}$. The area of the aqueous barrier was assumed to be that of a smooth cylinder that had the diameter and length of the inner surface of the gut. This surface area was calculated by determining the radius from the length $(L)$ of the segment $(20 \mathrm{~cm})$ and the luminal volume $(v)$ (measured at the end of each study):

area $=2 \sqrt{\pi v L}$

Total resistance to absorption per $\mathrm{cm}^{2}$ of area $\left(R_{\text {Tot }}\right)$ is the reciprocal of clearance $/ \mathrm{cm}^{2}$ :

$R_{\text {Tot }}=1 /\left(\right.$ clearance $\left./ \mathrm{cm}^{2}\right)$.

This $R_{\text {Tot }}$ is created by the resistance of the aqueous luminal barrier $\left(R_{\mathrm{Lum}}\right)$ and the epithelial cell $\left(R_{\mathrm{Ep}}\right)$ in series:

$R_{\mathrm{Tot}}=R_{\mathrm{Lum}}+R_{\mathrm{Ep}}$.

Calculation of either $R_{\mathrm{Lum}}$ or $R_{\mathrm{Ep}}$ requires quantitation of one of these two resistances. However, if epithelial transport is very rapid relative to diffusion through the luminal barrier, $R_{\mathrm{Ep}}$ becomes trivial relative to $R_{\text {Lum }}$. For the initial estimation of $R_{\text {Lum }}$, we assumed that the $R_{\mathrm{Ep}}$ for glucose or $\left[{ }^{14} \mathrm{C}\right]$ warfarin was negligible. Therefore:

$R_{\mathrm{Tot}}=R_{\mathrm{Lum}}$

This maximal estimate of $R_{\mathrm{Lum}}$ can be converted to a maximal thickness of an aqueous layer (unstirred layer) that would yield this resistance:

unstirred layer thickness $=\left(R_{\mathrm{Lum}}\right) \cdot(D)$,

where $D$ is the aqueous diffusion coefficient of the probes.

The unstirred layer in the human gut was similarly calculated from perfusion studies measuring glucose absorption from solutions containing $540 \mathrm{mg} / \mathrm{dl}$ ( $30 \mathrm{mM}$ ) or less. The diffusing area of the unstirred layer was calculated from the length of the perfused segment and a gut volume of $3 \mathrm{ml} / \mathrm{cm}$, an average value reported for the human small intestine perfused at a rate of $14 \mathrm{ml} / \mathrm{min}(21)$. A gut distended with 3 $\mathrm{ml} / \mathrm{cm}$ has a surface area at the villous tips of $\sim 6 \mathrm{~cm}^{2} / \mathrm{cm}$ (Eq. 2). The logarithmic mean glucose concentration in the lumen was calculated from inflow and outflow concentrations (determined from percentage of glucose absorbed assuming negligible net water movement).

Estimation of $R_{E p}$. The magnitude of $R_{\mathrm{Ep}}$ can be estimated for any glucose absorption rate from knowledge of the glucose concentration and flow rate of the infusate, the $V_{\max }$ and the true $K_{\mathrm{m}}$ for glucose transport, and absorbtive surface area. True $K_{\mathrm{m}}$ refers to the $K_{\mathrm{m}}$ that would be observed if there were no unstirred water layer. The observed value of $V_{\max }$ for constantly perfused 30 -cm segments of human gut is $\sim 24 \times 10^{-4} \mathrm{mmol} \cdot \mathrm{cm}^{-1} \cdot \mathrm{s}^{-1}$. Using a value for gut surface area of 6 $\mathrm{cm}^{2} / \mathrm{cm} \mathrm{(5),}, V_{\max }$ is $\sim 4 \times 10^{-4} \mathrm{mmol} \cdot\left(\mathrm{cm}^{2}\right)^{-1} \cdot \mathrm{s}^{-1}$. Lacking values for true $K_{\mathrm{m}}$ of glucose transport by the human mucosa, as a first approximation we used the reported value for rat small bowel which is $4.5 \mathrm{mM}(18)$.

The theory underlying the calculation of unstirred layer thickness for varying absorption rates of glucose is as follows. The rate of glucose absorption was calculated numerically because the saturability of the glucose transport system introduces a nonlinearity. Luminal fluid was assumed to be perfectly mixed in the radial direction up to an unstirred layer of thickness $d$. The perfused intestine is a steady-state preparation so that, at any position along the radial axis $(x)$, the diffusive flux through the unstirred layer must equal the rate of absorption by the active transport system;

$(D / d)\left(C_{\mathrm{Lum}}-C_{\mathrm{W}}\right)=\left(V_{\max } C_{\mathrm{w}}\right) /\left(C_{\mathrm{w}}+K_{\mathrm{m}}\right)$,

where $C_{\mathrm{Lum}}$ and $C_{\mathrm{w}}$ are the concentrations in the stirred lumen, and at the mucosal cell at position $x$, respectively, $D$ is the diffusion coeffcient of glucose $\left(6.7 \times 10^{-6} \mathrm{~cm}^{2} / \mathrm{s}\right), V_{\max }$ is the maximum absorption rate per unit area, and $K_{\mathrm{m}}$ is the dissociation constant of the glucose transport system or the Michaelis constant. This equation assumes that axial diffusion in the lumen is negligible. Solving Eq. 7 for $C_{\mathrm{W}}$ :

$C_{\mathrm{w}}=0.5\left(-b+\sqrt{b^{2}+4 C_{\mathrm{Lum}} K_{\mathrm{m}}}\right) \quad b=K_{\mathrm{m}}+\left(V_{\max } d / D\right)-C_{\mathrm{Lum}}$.

For a well mixed, cross-sectional ring of bulk luminal contents of thickness $\delta$ at the position $x$, conservation of mass yields:

$$
F[C(x)-C(x+\delta)]=\left[C(x)-C_{\mathrm{w}}\right](2 \pi a \delta) D / d,
$$

where $a$ is the radius of the intestine, $F$ is the perfusion rate and $C_{\mathrm{w}}$ is given by Eq. 8 .

Solving for $C(\mathrm{x}+\delta)$ :

$C(x+\delta)=C(x)-\left[C(x)-C_{\mathrm{W}}(x)\right](2 \pi a \delta D / F d)$.

Eq. 10 gives the concentration at position $x+\delta$ in terms of the concentration at $x$. Repeated application of this equation yields the concentration down the length of the lumen, and the concentration at the end of the loop $(x=L)$ indicates the net amount of glucose that was absorbed. The solution in the text was carried out for a $\delta$ of $1 / 100$ the length of the loop.

The concentration profile of glucose in the intervillous space. Winne (23) has presented a general derivation of the concentration profile that results from the absorption of solute along the lateral surfaces of the villi. These results will be applied here with the following assumptions: $(a)$ the villi are a series of parallel, rectangular columns; $(b)$ the luminal space is perfectly stirred up to the villous tips; $(c)$ movement of the solute in the intervillous space is due entirely to diffusion; $(d)$ solute concentration over any cross-sectional area of the intervillous space is relatively constant; $(e)$ absorption occurs only on the lateral surface of the villi and absorption at the villous tips is neglected; $(f)$ the product of the villous membrane permeability $(P)$ and the surface area per unit villous length $(S)$ is a constant, independent of the distance from the villuos tips $(X)$; and $(g)$ the length of the intervillous space is much longer than the space constant $q$ (see below). With these assumptions, the general expression of Winne (23) for the concentration $\mathrm{C}(\mathrm{X})$ at a distance $X$ from the villous tip relative to the luminal concentration $\left(C_{\mathrm{Lum}}\right)$ is:

$C(X) / C_{\mathrm{L}}=e^{-\mathrm{X} / \mathrm{q}} \quad q^{2}=D A_{\mathrm{s}} /(P S)$,

where $D$ is the diffusion coefficient and $A_{\mathrm{s}}$ is the intervillous space cross-sectional area. To the extent that the above assumptions are not 
Table I. Absorption and Resistance Data for Glucose and $\left[{ }^{14} \mathrm{C}\right]$ Warfarin in the Jejunum of the Dog*

\begin{tabular}{|c|c|c|c|c|c|c|}
\hline Probe & $\begin{array}{l}\text { Perfusion } \\
\text { rate }\end{array}$ & $n$ & Absorption & Clearance $/ \mathrm{cm}^{2}$ & Maximal $R_{\text {Lum }}$ & $\begin{array}{c}\text { Maximal unstirred } \\
\text { layer }\end{array}$ \\
\hline & & & $\%$ & $\mathrm{~cm} / \mathrm{min}$ & $\mathrm{min} / \mathrm{cm}$ & $\mu m$ \\
\hline \multirow[t]{2}{*}{ Glucose } & 5 & 3 & $62 \pm 3$ & $0.096 \pm 0.012$ & $11 \pm 1.1$ & $57 \pm 6$ \\
\hline & 26 & 3 & $46 \pm 6$ & $0.16 \pm 0.05$ & $7.5 \pm 2.2$ & $39 \pm 11$ \\
\hline \multirow[t]{2}{*}[{}^{14}\mathrm{C}]{ Warfarin } & 5 & 3 & $60 \pm 2$ & $0.092 \pm 0.01$ & $12 \pm 1.3$ & $50 \pm 5$ \\
\hline & 26 & 3 & $47 \pm 8$ & $0.17 \pm 0.06$ & $7.7 \pm 2.8$ & $33 \pm 12$ \\
\hline
\end{tabular}

* Data are mean \pm 1 SEM.

totally correct (in particular $(b),(c)$, and $(e)$ ), our calculated diffusion distance in the intervillous space will overestimate the actual diffusion distance.

The concentration decreases exponentially with distance from the tip (Eq. 11). The distance that glucose penetrates down the intervillous space is characterized by the constant $q$. The greater the absorption rate, the larger the cell permeability $(P)$, the smaller the $q$, and the shorter the distance of penetration (Eq. 11). The absorption rate can be related to an alternate case where the villus tips have an infinite permeability so that the concentration is 0 at the villus tips and the absorption is limited entirely by an unstirred layer of luminal fluid of thickness $d$ :

$Q=\left(D A_{\mathrm{t}} / d\right) C_{\mathrm{Lum}}$

where $A_{\mathrm{t}}$ is the total surface area, i.e., the surface of a circular cylinder whose radius corresponds to the position of the villous tips. Equating Eqs. 11 and 12 and solving for $P S$ :

$P S=\frac{D A_{\mathrm{t}}^{2}}{d^{2} A_{\mathrm{s}}}$.

Substituting this expression for PS into the equation for $q(11)$ :

$q=\left(A_{\mathrm{s}} / A_{\mathrm{t}}\right) d$.

To estimate the ratio of the cross-sectional surface area of the intervillous space to the total surface area at the villous tips $\left(A_{\mathrm{s}} / A_{\mathrm{t}}\right)$, dog jejunum was cannulated and the lumen flushed with isotonic saline. The saline was stripped from the segment and the distal end occluded. Formalin (3\%) was then instilled into the segments at volumes of 1 or $3 \mathrm{ml} / \mathrm{cm}$ (the latter volume was greater than observed in any study). After $24 \mathrm{~h}$ in formalin, the emptied segments maintained the diameter present in the distended state. The segments were embedded, sectioned, stained, and examined by light microscopy.

\section{Results}

Unstirred layer thickness. The results of studies in dogs are summarized in Table I. The volume of luminal contents, respectively, averaged $0.45 \pm 0.05$ and $1.8 \pm 0.5 \mathrm{ml} / \mathrm{cm}$ for 5 and $26 \mathrm{ml} / \mathrm{min}$ perfusion rates. The clearances of both glucose and $\left[{ }^{14} \mathrm{C}\right]$ warfarin were $\sim$ twice as rapid when the gut was perfused at $26 \mathrm{ml} / \mathrm{min}$ compared with $5 \mathrm{ml} / \mathrm{min}$ and $R_{\text {Lum }}$ was $\sim 50 \%$ less with the more rapid perfusion. At a perfusion rate of $5 \mathrm{ml} / \mathrm{min}$, the maximal unstirred layer thickness (calculated on the basis of negligible $R_{\mathrm{Ep}}$ [Eq. 6]) averaged $57 \pm 6$ for glucose and $50 \pm 5 \mu \mathrm{m}$ for $\left[{ }^{14} \mathrm{C}\right]$ warfarin. At a perfusion rate of $26 \mathrm{ml} / \mathrm{min}$, the unstirred layer averaged $39 \pm 11$ for glucose and $33 \pm 12 \mu \mathrm{m}$ for $\left[{ }^{14} \mathrm{C}\right]$ warfarin.

The unstirred layer thicknesses (calculated from Eqs. 2 and 6) for nine previous studies of glucose absorption in human subjects are shown in Table II. These values ranged from 23 to $65 \mu \mathrm{m}$, averaging $40 \mu \mathrm{m}$.

Estimation of $\mathbf{R}_{E p}$ versus $\mathbf{R}_{L u m}$ for glucose absorption. Fig. 1 plots the unstirred layer thickness in man that would account for absorption rate of glucose from an infusate containing 500 $\mathrm{mg} / \mathrm{dl}(28 \mathrm{mM})$ glucose (22). $R_{\mathrm{Ep}}$ to glucose was calculated using a value of $4.5 \mathrm{mM}$ for true $K_{\mathrm{m}}(18)$. The three curves represent the relation between absorption rate and unstirred layer for values of $V_{\max }$ of infinity, $4 \times 10^{-4}$ $\mathrm{mmol} \cdot\left(\mathrm{cm}^{2}\right)^{-1} \cdot \mathrm{s}^{-1}$ (the reported value for the human gut) (22) and $4 \times 10^{-5} \mathrm{mmol} \cdot\left(\mathrm{cm}^{2}\right)^{-1} \cdot \mathrm{s}^{-1}$ (one-tenth the reported value). By definition, $R_{\mathrm{Ep}}$ is negligible at infinite $V_{\max }$, therefore unstirred layer thickness provides the total resistance to absorption. The horizontal distance between the infinite $V_{\max }$ curve and the other two curves reflect $R_{\mathrm{Ep}}$ for a given glucose absorption rate. Note that for a $V_{\max }$ of $4.5 \times 10^{-4}$ $\mathrm{mmol} \cdot\left(\mathrm{cm}^{2}\right)^{-1} \cdot \mathrm{s}^{-1}$, the plot is virtually identical to that for infinite $V_{\max }$, indicating a negligible $R_{\mathrm{Ep}}$, and that $R_{\text {Tot }}$ results entirely from the unstirred layer. Even if $V_{\max }$ were one-tenth the value cited in the literature, $R_{\mathrm{Ep}}$ would represent only a minor fraction ( $\sim 20 \%$ ) of $R_{\text {Tot }}$ for the $75 \%$ absorption rate observed by Holdsworth and Dawson (22).

Fig. 2 shows plots similar to those in Fig. 1 but for a fixed $V_{\max }\left(4 \times 10^{-4} \mathrm{mmol} \cdot\left(\mathrm{cm}^{2}\right)^{-1} \cdot \mathrm{s}^{-1}\right)$ and a varying $K_{\mathrm{m}}$. Note that even if the $K_{\mathrm{m}}$ in man or dog were fivefold greater than the

Table II. Literature Values for Glucose Absorption from the Human Intestine Determined from Constant Perfusion Studies

\begin{tabular}{|c|c|c|c|c|c|}
\hline Author (reference) & $\begin{array}{l}\text { Segment } \\
\text { length }\end{array}$ & $\begin{array}{l}\text { Infusion } \\
\text { rate }\end{array}$ & [GLUC] & Absorption & $\begin{array}{c}\text { Maximal } \\
\text { unstirred } \\
\text { layer }\end{array}$ \\
\hline & $\mathrm{cm}$ & $m L / m i n$ & $m M$ & $\%$ & $\mu m$ \\
\hline Sladen (31) & 30 & 20 & 5.6 & 73 & 37 \\
\hline Brown (27) & 25 & 9.6 & 14 & 81 & 52 \\
\hline Frase (10) & 20 & 13 & 25 & 53 & 65 \\
\hline Frase $(10)^{*}$ & 20 & 13 & 25 & 81 & 30 \\
\hline Flourie (9) & 25 & 10 & 30 & 97 & 23 \\
\hline Holdsworth (22) & 30 & 20 & 28 & 75 & 34 \\
\hline Gray $(28)^{\ddagger}$ & 15 & 15 & 10 & 56 & 42 \\
\hline Malawer (29) & 30 & 11.7 & 6.4 & 90 & 37 \\
\hline Rey (30) & 20 & 7.5 & 18 & 74 & 42 \\
\hline Mean & & & & & 40 \\
\hline
\end{tabular}

* Cystic fibrosis patients.

‡ Absorption from sucrose (hydrolysis not rate limiting). 


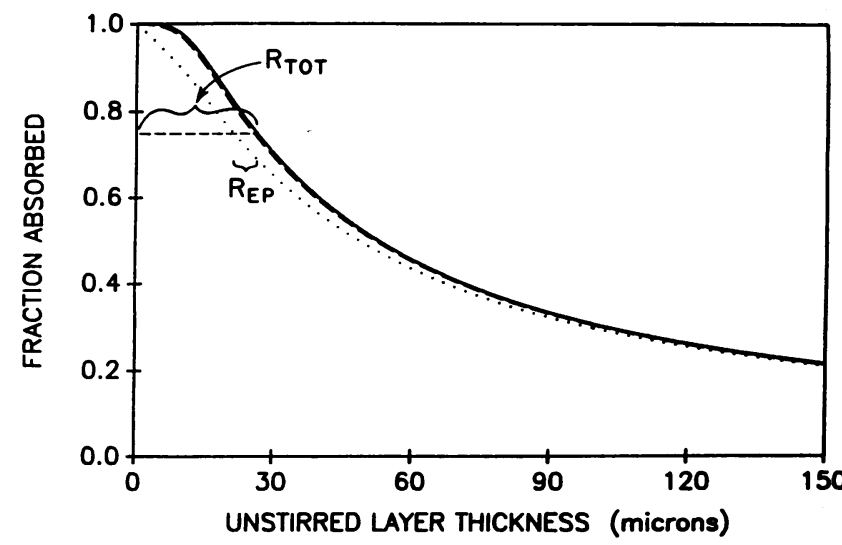

Figure 1. The unstirred layer thickness that would yield a given fractional absorption of glucose for varying $V_{\max }$ of epithelial transport of glucose. The experimental conditions are those used by Holdsworth and Dawson in perfusion studies of the normal human jejunum (22): infusion rate of $20 \mathrm{ml} / \mathrm{min} ; 30-\mathrm{cm}$ segment; inflow concentration of glucose $500 \mathrm{mg} / \mathrm{dl}$. Surface area assumed to be $6 \mathrm{~cm}^{2} / \mathrm{cm}$ of length (21). A $K_{\mathrm{m}}$ of $4.5 \mathrm{mM}$, the value reported for the rat (18), was used. The upper curve (-) is for the case where epithelial transport is very rapid (infinite $V_{\max }$ ) and the unstirred layer is totally rate limiting. The second curve $(--)$ is for a $V_{\max }$ of $4 \times 10^{-4}$ $\mathrm{mmol} \cdot\left(\mathrm{cm}^{2}\right)^{-1} \cdot \mathrm{s}^{-1}$ the value determined experimentally by Holdsworth and Dawson (22). This curve is virtually identical to infinite $V_{\max }$ curve. The bottom curve $(\cdots)$ is for a $V_{\max }$ of $4 \times 10^{-5}$ $\mathrm{mmol} \cdot\left(\mathrm{cm}^{2}\right)^{-1} \cdot \mathrm{s}^{-1}$, one-tenth the literature value. The horizontal distance between the curves indicate $R_{\mathrm{Ep}}$ in units of micrometers of unstirred layer. At the $75 \%$ absorption observed by Holdsworth and Dawson, $R_{\mathrm{Ep}}$ is negligible for a $V_{\max }$ of $4 \times 10^{-4} \mathrm{mmol} \cdot\left(\mathrm{cm}^{2}\right)^{-1} \cdot \mathrm{s}^{-1}$ and only $\sim 20 \%$ of the total resistance at $4 \times 10^{-5} \mathrm{mmol} \cdot\left(\mathrm{cm}^{2}\right)^{-1} \cdot \mathrm{s}^{-1}$.

value reported for rats, $R_{\mathrm{Ep}}$ would be nearly negligible for the $75 \%$ glucose absorption rate. If the $K_{\mathrm{m}}$ were tenfold greater than the value reported for the rat, $\sim 20 \%$ of the resistance to absorption would result from $R_{\mathrm{Ep}}$ for $75 \%$ glucose absorption.

Surface area of intervillous space. Fig. 3 shows a typical microscopical section of the villi of a dog jejunal segment distended with $1 \mathrm{ml} / \mathrm{cm}$ of saline, a value greater than the average distension observed at a perfusion rate of $5 \mathrm{ml} / \mathrm{min}$ and less than that observed at $25 \mathrm{ml} / \mathrm{min}$. The width of the intervillous space averages $40 \mu \mathrm{m}$ and is roughly one-half the width of the villi. The mucosal epithelial cell is $\sim 30 \mu \mathrm{m}$ thick in the dog, as is the epithelial cell of man determined from published photomicrographs of the human jejunal mucosa.

Concentration profile in the intervillous space. As shown in equations 11 and 12, the concentration profile down the intervillous space is a function of the thickness of an unstirred layer over the villous tips that would account for observed absorption and the ratio of the cross-sectional surface area of the intervillous space to the total surface area. Fig. 4 shows the resultant concentration profile of glucose in the intervillous space using intervillous/villous tip total surface area ratios of 1:3 (observed) and 1:2 (a maximal estimate), and a $40 \mu \mathrm{m}$ equivalent unstirred layer thickness.

\section{Discussion}

The thickness of the unstirred layer in the small intestine has been measured using several different techniques in various in vivo and in vitro preparations. In vivo measurements in rats generally have yielded unstirred layers of at least $300 \mu \mathrm{m}$ thickness $(3,11,14-17)$, and in man and dogs this layer is said to be greater than $600 \mu \mathrm{m}(9,10,12,13)$.

In this study, we intubated the jejunum of unanesthetized dogs and measured $R_{\text {Lum }}$ using glucose or $\left[{ }^{14} \mathrm{C}\right]$ warfarin as probes. The results obtained (see Table I) are less than onesixth the values cited for unstirred layers in rats and less than one-tenth that for man. We believe this enormous discrepancy reflects differences both in methodology and animal models.

Two different methods commonly have been employed to measure unstirred layer thickness. The osmotic transient technique was first used to measure the thickness of a layer of fluid that remained in the gall bladder after drainage and replacement by a fluid of differing osmolality (24). In this application, the bulk luminal fluid could be rapidly switched from a fluid of one osmolality to a second of different osmolality, leaving a homogenous "boundary layer" of initial fluid in the gall bladder. Thus, this technique presumably yielded accurate measurements of the thickness of fluid that was not washed out with refilling the gall bladder. However, this value could bear little relationship to the unstirred layer during steady-state absorption. For example, the poor luminal stirring that would exist in the noncontracting gall bladder should yield a much thicker unstirred layer than the $200 \mu \mathrm{m}$ indicated by the osmotic transient technique.

This technique was then applied to the small intestine of rats $(11,15)$ and man $(9,10,12)$. A constant infusion of one solution was switched to a solution of differing osmolality and the one-half time to a new, stable PD was measured. In this situation there is no boundary layer of initial fluid. Rather, the entire lumen must be washed out by the second fluid to establish a new steady-state PD. Even if no unstirred layer existed,

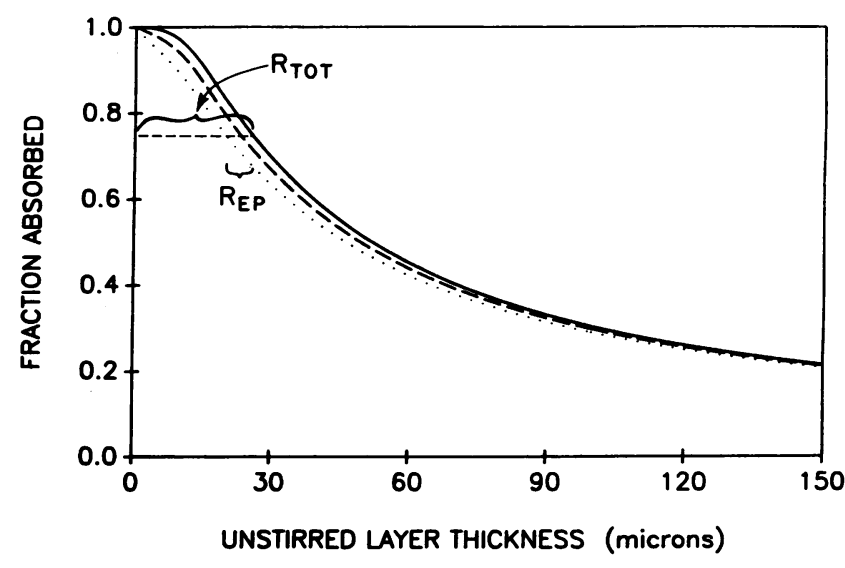

Figure 2. Plots are similar to those of Fig. 1 but show the influence of varying dissociation constants $\left(K_{\mathrm{m}}\right)$ on the unstirred layer that would exist for fractional absorptions of glucose. For all curves, $V_{\max }$ is $4 \times 10^{-4} \mathrm{mmol} \cdot\left(\mathrm{cm}^{2}\right)^{-1} \cdot \mathrm{s}^{-1}(22)$. The top curve (-) is for $K_{\mathrm{m}}$ of $4.5 \mathrm{mM}$ (the value reported for the rat intestine (18) and the value used in Fig. 1). This curve was nearly identical to the infinite $V_{\max }$ curve (see Fig. 1). The curves for a $K_{\mathrm{m}}$ of $22.5 \mathrm{mM}(--)$ and $44.5 \mathrm{mM}(\cdots)$ indicate that even if the $K_{\mathrm{m}}$ were 5 or 10 times larger than the value for the rat, the epithelium would still represent only $\sim 10$ and $20 \%$ of the total resistance to the $75 \%$ absorption observed by Holdsworth and Dawson (22). 


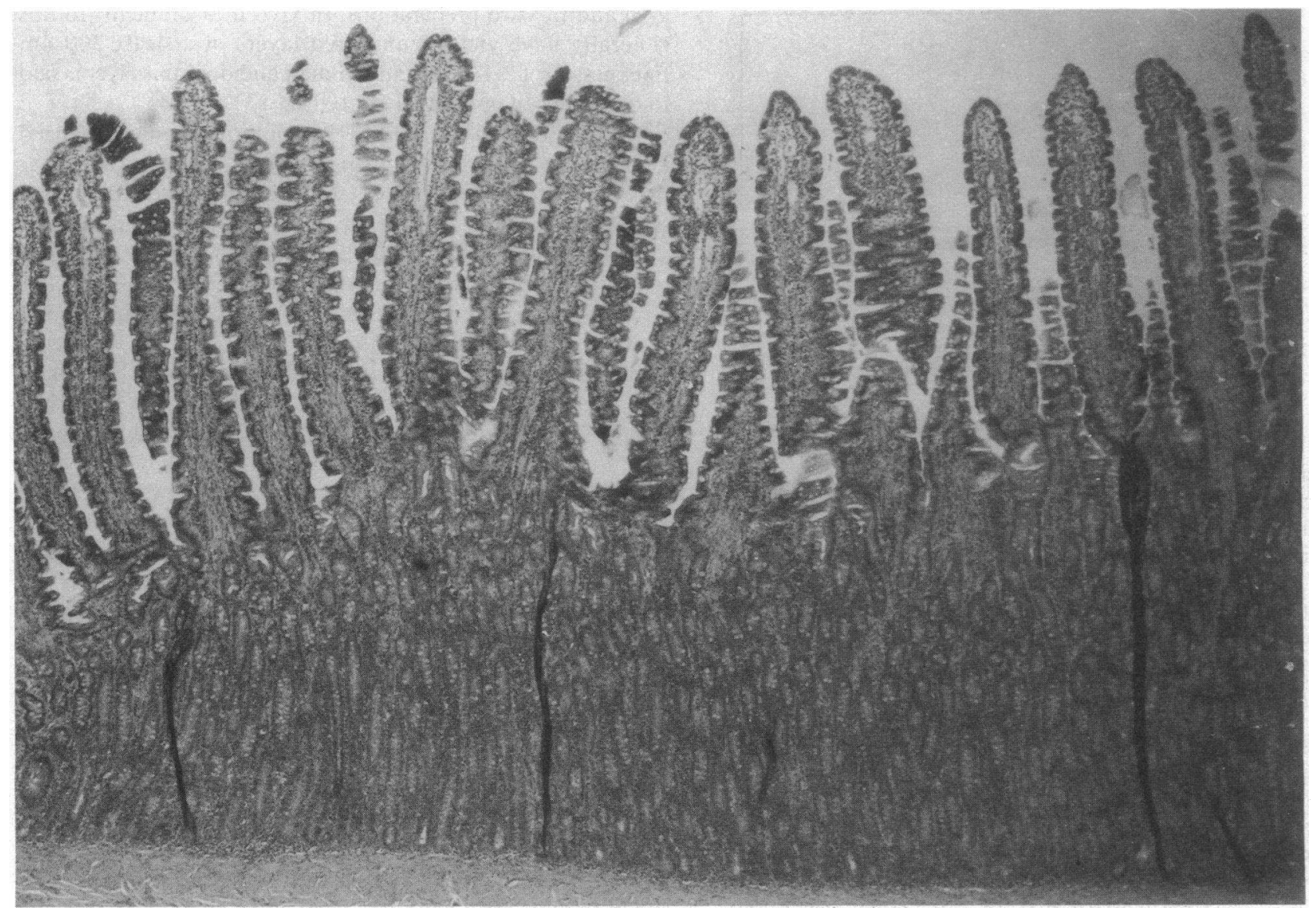

Figure 3. Microscopical section of dog villi $(\times 50)$ from a jejunal segment distended with $1 \mathrm{ml} / \mathrm{cm}$. The cross-sectioned area of the intervillous space is roughly one-half of that of the villous tips.

considerable time would be required to bring the luminal osmolality to that of the second solution. In addition, the solutes used to manipulate osmolality presumably have to diffuse down the extent of the intervillous space before a steady-state PD is established. In contrast, rapidly transported solutes are absorbed at the villus tips. Thus the greater than $600 \mu \mathrm{m}$ unstirred layers reported for the human gut may have little relevance to the unstirred layer that exists for rapidly absorbed compounds.

The second method employs the rate of absorption or brush border hydrolysis of probes to calculate unstirred layer thickness $(3,14-18)$. These measurements are carried out during a steady-state perfusion and require few assumptions for accuracy. In this technique, the rate of absorption or hydrolysis is used to measure $R_{\mathrm{Tot}}$ and subtraction of $R_{\mathrm{Ep}}$ or hydrolysis yields $\boldsymbol{R}_{\mathrm{Lum}}$.

With two recent exceptions, such studies have been performed in rats using segments of small bowel exposed at laparotomy and yielded unstirred layers ranging from 300 to 1,000 $\mu \mathrm{m}(3,11,14-17)$. However, in conscious, nonlaparotomized rats we found an unstirred layer of only $\sim 100 \mu \mathrm{m}(19)$, in contrast to $>600 \mu \mathrm{m}$ values in comparable segments studied at laparotomy. Similarly, Yuasa et al. (26) found a much lower $\boldsymbol{R}_{\text {Lum }}$ for gut segments replaced in the abdomen and studied after the rat regained consciousness. Thus, the $>300-\mu \mathrm{m}$ unstirred layers reported for rats appear to be an artefact of the poor motility induced by laparotomy.

In this study, we calculated unstirred layer thickness for the dog from measurements of glucose and $\left[{ }^{14} \mathrm{C}\right]$ warfarin absorption using the assumption that $R_{\mathrm{Ep}}$ was negligible, an assumption that gives a maximal $R_{\mathrm{Lum}}$. This maximal estimate of $\boldsymbol{R}_{\text {Lum }}$ was equivalent to an unstirred layer over the villous tips of only $\sim 50$ and $35 \mu \mathrm{m}$ at perfusion rates of 5 and $26 \mathrm{ml} /$ min, respectively (Table I).

All previous unstirred layer measurements in the human gut employed the osmotic transient technique. However, maximal estimates of unstirred layer thickness in man can be easily obtained from previous reports of glucose absorption from infusates containing low concentrations of glucose $(9$, $10,22,27-31$ ). For this calculation, $R_{\mathrm{Ep}}$ was assumed to be negligible and the area of the luminal aqueous barrier was assumed to have an area equal to a cylinder over the villous tips. As shown in Table II, the maximal thickness of unstirred layer in the human intestine averaged $40 \mu \mathrm{m}$ (range: 23 to 65 $\mu \mathrm{m})$, a value roughly $1 / 15$ that reported for man using the osmotic transient technique. Indeed, in two osmotic transient studies $(9,10)$, our calculation of the unstirred layer from glucose absorption gave a value of $\sim 40 \mu \mathrm{m}$ while simultaneous application of the osmotic transient technique yielded values greater than $600 \mu \mathrm{m}$. 


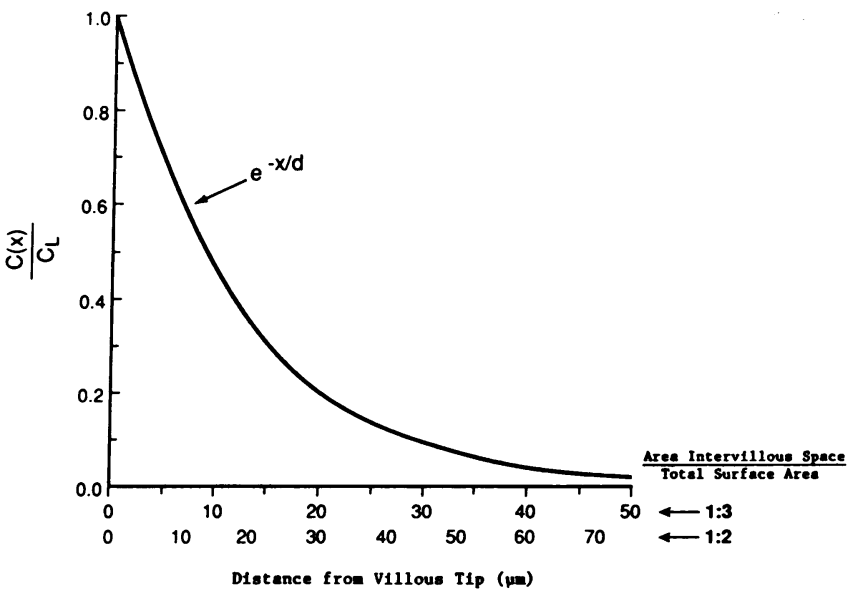

Figure 4. Concentration profile of glucose down the intervillous space, calculated from Eq. 12. Data are provided for ratios of intervillous/villous tip cross sectional areas of $1: 3$ and $1: 2$. $C(x)$ is concentration at distance $(x)$ from the villous tip; $C_{\mathrm{L}}$ is the concentration in bulk luminal contents, and $d$ is the space constant (see Eq. 11 ). It is apparent that virtually all glucose absorption occurs very near the villous tips.

It should be stressed that calculation of maximal unstirred layer thickness from absorption measurements is dependent upon just one assumption, that one knows the glucose absorption rate per $\mathrm{cm}^{2}$ of unstirred layer. Since glucose absorption is directly measured, the only possible error is in the area calculation.

Previous publications have used surface area values for the unstirred layer ranging from a smooth cylinder (a minimum value) to the total villous surface (a maximal value). The rationale underlying our surface area calculation is depicted in the models shown in Fig. 5. In model $5 A$, glucose transport by the epithelium is extremely rapid and glucose concentration is negligible at the villous tips. This could result from rapid absorption by the villous tip cells and/or convection of glucose into the intervillous space via villous contractions, with rapid transport from the intervillous space. In either situation, the rate-limiting step in absorption is diffusion through a cylinder of unstirred layer overlying the villous tips. Since our calculations based on $K_{\mathrm{m}}$ and $V_{\max }$ (Figs. 1 and 2) indicated minimal epithelial resistance to glucose absorption, it seems appropriate to use a surface area for the unstirred layer equal to that of a cylinder at the villous tips. This area yields the unstirred layers shown in Tables I and II.

Some investigators have used the entire villous surface area to calculate unstirred layer thickness. Since this area is $\sim 10$ times that of the tips, one obtains an unstirred layer of $\sim 400$ $\mu \mathrm{m}$, rather than $40 \mu \mathrm{m}$, for our data. However, a simple analysis of villous architecture indicates that this calculation is illogical. In order for the unstirred layer to have the area of the entire villous surface, bulk luminal contents must be convected down the extent of the intervillous space which has a width of only $\sim 40 \mu \mathrm{m}$. Thus, it is physically impossible for the unstirred layer to exceed $20 \mu \mathrm{m}$ in thickness when the sides of the villi surface are exposed to solute via convection.

Fig. $5 B$ depicts the situation where uptake is limited both by an unstirred layer over the villous tips and epithelial transport. Solute concentration rises at the villous tips, resulting in diffusion into the intervillous space. There are now two distinct aqueous diffusion barriers: (a) a layer over the villous tips and (b) a longitudinal barrier produced by unstirred intervillous fluid. For a given absorption rate, the thickness of the layer over the tips must decrease with increasing epithelial resistance.

While it is difficult to model the intervillous fluid column as a "layer," a functional unstirred layer could be defined as
A

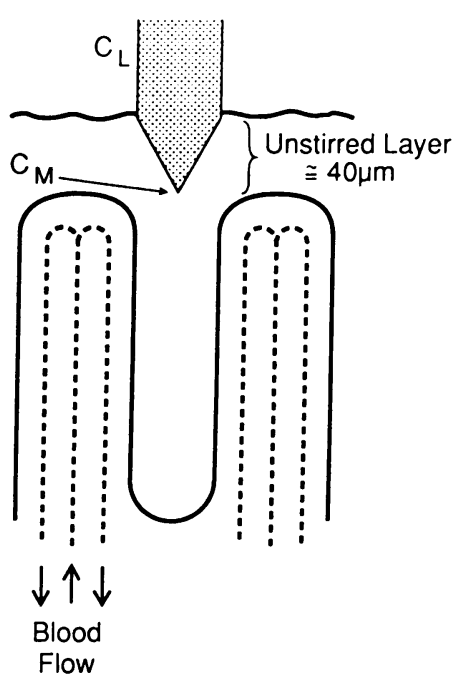

B

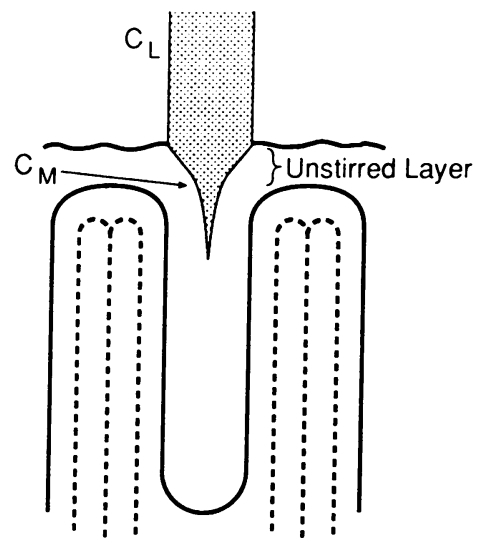

C

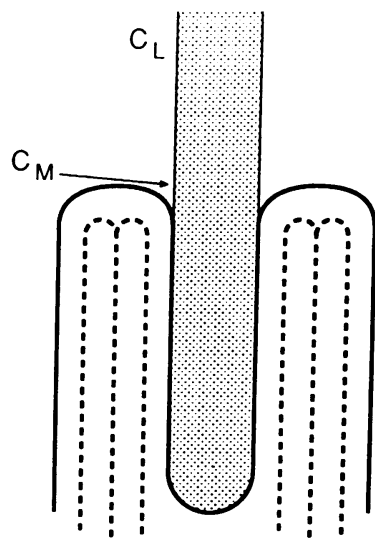

Figure 5. Models of aqueous diffusion barrier for glucose. The concentration of glucose is represented by the width of the arrow. In model $A$, glucose transport by the epithelium is very rapid and glucose concentration at the villous tips is negligible relative to that of bulk luminal contents. In this model, glucose uptake is limited solely by the unstirred layer over the villous tips, a layer with a calculated thickness of $\sim 40 \mu \mathrm{m}$ in dogs and man. Model $B$ reflects the situation in which epithelial transport limits absorption. In this situation, glucose concentration rises at the villous tips and glucose diffuses into the intervillous space. There are two aqueous barriers to absorption: the fluid layer over the villous tips and the column of fluid in the intervillous space. Fig. $5 C$ reflects the maximal diffusion barrier for a solute in which epithelial transport is so slow that the concentration of solute is constant throughout the unstirred layer and the intervillous space. 
the mean longitudinal distance solute diffuses down this space before being absorbed. This distance is maximal when there is no unstirred layer over the villous tips and all absorption occurs from the sides of the villi. This distance can be roughly estimated for low concentrations of glucose if simplifying assumptions are employed regarding the anatomy of this space (see Methods). Using the observed 1:3 ratio of the cross-sectional surface area of intervillous space to the luminal mucosal surface, $50 \%$ of the glucose will be absorbed within $9 \mu \mathrm{m}$ of the villous tips and $>90 \%$ within $40 \mu \mathrm{m}$ of the tips (see Fig. 4). Thus, a rapidly absorbed solute ( such as glucose at low luminal concentration) will have a mean aqueous diffusion barrier of $40 \mu \mathrm{m}$ or less, independent of whether absorption occurs at the villous tips or along the sides of the villi.

It follows from the above that a single value cannot represent the aqueous diffusion barrier for all solutes. Compounds with a ratio of $R_{\mathrm{Ep}}$ :aqueous diffusion coefficient appreciably greater than glucose, will diffuse more deeply into the intervillous space. While this diffusion distance may become appreciable, the long aqueous diffusion path is caused by the slow epithelial transport rather than being the cause of the slow transport. This concept can be carried to its illogical extreme if one considers a solute whose epithelial uptake is so slow that a constant concentration develops throughout the entire intervillous space (Fig. $5 \mathrm{C}$ ). The mean distance that absorbed solute would have to diffuse before absorption would be $\sim 300 \mu \mathrm{m}$ (one-half the length of the intervillous space). However, this long diffusion distance is irrelevant to absorption, which is limited by epithelial transport.

All luminal resistance data for the dog and man in Tables I and II are calculated assuming $R_{\mathrm{Ep}}$ to be negligible for glucose and $\left[{ }^{14} \mathrm{C}\right]$ warfarin. It is possible to estimate the magnitudes of $R_{\mathrm{Ep}}$ and $R_{\mathrm{Lum}}$ for glucose if $R_{\mathrm{Lum}}$ is assumed to be an unstirred layer over the villi. This calculation depends upon knowledge of infusate glucose concentration and percentage of absorption (two readily measured values), and $V_{\max }$ and true $K_{\mathrm{m}}$ of glucose transport by the epithelium. Values for $V_{\max }$ are available for humans but there appears to be no values for true $K_{\mathrm{m}}$ in humans or dogs. Using literature values for the true $K_{\mathrm{m}}$ of rat intestine, $R_{\mathrm{Ep}}$ was negligible for infusate glucose concentrations of $540 \mathrm{mg} / \mathrm{dl}(30 \mathrm{mM})$ or less (Figs. 1 and 2). Even if the $V_{\max }$ of man was $1 / 10$ the literature value (Fig. 1) or the true $K_{\mathrm{m}}$ were 10 times greater than that of the rat (Fig. 2), $R_{\mathrm{Ep}}$ is minimal. Thus, our maximal estimates for $R_{\text {Lum }}$ or unstirred layer thickness from glucose absorption data should be close to the true values.

We conclude that for the normally absorbing gut epithelium, measurement of glucose absorption at low glucose concentration provides a simple, straightforward means of assessing $R_{\mathrm{Lum}}$ or unstirred layer thickness. Application of this technique indicates an unstirred layer thickness for man of $40 \mu \mathrm{m}$ or less. Nevertheless, for rapidly transported compounds, such as low concentrations of glucose, diffusion through a $40-\mu \mathrm{m}$ preepithelial diffusion barrier remains the rate limiting step in absorption. Passively absorbed compounds must diffuse through an $\sim 30-\mu \mathrm{m}$ aqueous thickness of the gut epithelia to reach the blood stream. This $30-\mu \mathrm{m}$ thickness represents a diffusion barrier at least $75 \%$ of the $40-\mu \mathrm{m}$ unstirred layer over the tips. Thus, epithelial resistance should comprise a minimum of $40 \%$ of the total resistance to absorption of passively absorbed compounds.

\section{Acknowledgments}

The authors acknowledge secretarial assistance of Ms. Patricia Kelly and Ms. Lucy Kraml, and technical assistance of Chester Sievert and Bonnie Abeyta.

This work was supported by funds from the Veterans Administration and the National Institute of Health (2R01-DK 13309-19).

\section{References}

1. Cerda, J. J., F. L. Robbins, C. W. Burgin, and G. A. Gereneser. 1987. Unstirred water layers in rabbit intestine: effects of guar gum. $J$. Parenteral. Enteral. Nutr. 11:63-66.

2. Hoyumpa, A. M., Jr., S. Nichols, S. Schenke, and F. A. Wilson. 1976. Thiamine transport in thiamine-deficient rats: role of the unstirred water layer. Biochim. Biophys. Acta. 406:438-447.

3. Levitt, M. D., J. M. Kneip, and D. G. Levitt. 1988. Use of laminar flow and unstirred layer models to predict intestinal absorption in the rat. J. Clin. Invest. 81:1365-1369.

4. Lukie, B. E., H. Westergaard, and J. M. Dietschy. 1974. Validation of a chamber that allows measurement of both tissue uptake rates and unstirred layer thicknesses in the intestine under conditions of controlled stirring. Gastroenterology. 67:652-661.

5. Sallee, V. L., and J. M. Dietschy. 1973. Determinants of intestinal mucosal uptake of short- and medium-chain fatty acids and alcohols. J. Lipid Res. 14:475-484.

6. Westergaard, H., and J. M. Dietschy. 1974. Delineation of the dimensions and permeability characteristics of the two major diffusion barriers to passive mucosal uptake in the rabbit intestine. J. Clin. Invest. 54:718-732.

7. Wilson, F. A., and J. M. Dietschy. 1974. The intestinal unstirred layer: its surface area and effect on active transport kinetics. Biochim. Biophys. Acta. 363:112-126.

8. Johnson, I. T., and J. M. Gee. 1981. Effect of gel-forming gums on the intestinal unstirred layer and sugar transport in vitro. Gut. 22:398-403

9. Flourie, B., N. Vidon, C. H. Florent, and J. J. Berneir. 1984. Effect of pectin on jejunal glucose absorption and unstirred layer thickness in normal man. Gut. 25:936-941.

10. Frase, L. L., A. D. Strickland, G. W. Kachel, and G. J. Krejs. 1985. Enhanced glucose absorption in the jejunum of patients with cystic fibrosis. Gastroenterology. 88:478-484.

11. Harris, M. S., J. W. Dobbins, and H. J. Binder. 1986. Augmentation of neutral sodium chloride absorption by increased flow rate in rat ileum in vivo. J. Clin. Invest. 78:431-438.

12. Read, N. W., D. C. Barber, R. J. Levin, and C. D. Holdsworth. 1977. Unstirred layer and kinetics of electrogenic glucose absorption in the human jejunum in situ. Gut. 18:865-876.

13. Ryu, K. H., and E. Grim. 1982. Unstirred water layer in canine jejunum. Am. J. Physiol. 242:G364-369.

14. Smithson, K. W., D. B. Millar, L. R. Jacobs, and G. M. Gray. 1981. Intestinal diffusion barrier: unstirred water layer or membrane surface mucous coat? Science (Wash. DC). 214:1241-1244.

15. Westergaard, H., K. H. Holtermuller, and J. M. Dietschy. 1986. Measurement of resistance of barriers to solute transport in vivo in rat jejunum. Am. J. Physiol. 250:G727-735.

16. Winne, D. 1976. Unstirred layer thickness in perfused rat jejunum in vivo. Experientia (Basel). 32:1278-1279.

17. Winne, D. 1979. Rat jejunum perfused in situ: effect of perfusion rate and intraluminal radius on absorption rate and effective unstirred layer thickness. Naunyn-Schmiedeberg's Arch. Pharmacol. 307:265-274.

18. Yuasa, H., Y. Miyamoto, T. Iga, and M. Hanano. 1986. Determination of kinetic parameters of a carrier-mediated transport in the perfused intestine by two-dimensional laminar flow model: effects of the unstirred water layer. Biochim. Biophys. Acta. 856:219-230.

19. Anderson, B. W., A. S. Levine, D. G. Levitt, J. M. Kneip, and 
M. D. Levitt. 1988. Physiological measurement of luminal stirring in perfused rat jejunum. Am. J. Physiol. 254:G843-848.

20. Dow, P. 1956. Estimations of cardiac output and central blood volume by dye dilution. Am. J. Physiol. Rev. 36:77.

21. Dillard, R. L., H. Eastman, and J. S. Fordtran. 1965. Volumeflow relationship during the transport of fluid through the small intestine. Gastroenterology. 49:58-66.

22. Holdsworth, C. D., and A. M. Dawson. 1964. The absorption of monosaccharides in man. Clin. Sci. (Lond.). 27:371-379.

23. Winne, D. 1978. The permeability coefficient of the wall of a villous membrane. J. Math. Biol. 6:95-108.

24. Diamond, J. M. 1966. A rapid method for determining voltage-concentration relations across membranes. J. Physiol. (Lond.) 183:83-100.

25. Levitt, M. D., T. Aufderheide, C. A. Fetzer, J. H. Bond, and D. G. Levitt. 1984. Use of carbon monoxide to measure luminal stirring in the rat gut. J. Clin. Invest. 74:2056-2064.

26. Yuasa, H., T. Iga, M. Hanano, and J. Watanabe. 1988. Com- parative assessment of the resistance of the unstirred water layer to solute transport between two different intestinal perfusion systems. Biochim. Biophys. Acta. 938:189-198.

27. Brown, B. D., and H. V. Ammon. 1981. Effect of glucose on jejunal water and solute absorption in the presence of glycodeoxycholate and oleate in man. Dig. Dis. Sci. 26:710-717.

28. Gray, G. M., and F. J. Ingelfinger. 1966. Intestinal absorption of sucrose in man: interrelation of hydrolysis and monosaccharide product absorption. J. Clin. Invest. 45:388-398.

29. Malawer, S. J., M. Ewton, J. S. Fordtran, and F. J. Ingelfinger. 1965. Interrelation between jejunal absorption of sodium, glucose, and water in man. J. Clin. Invest. 44:1072-1073.

30. Rey, F., F. Drillet, J. Schmitz, and J. Rey. 1974. Influence of flow rate on kinetics of the intestinal absorption of glucose and lysine in children. Gastroenterology. 66:79-85.

31. Sladen, G. E., and A. W. Dawson. 1969. Interrelationships between absorption of glucose, sodium and water by the normal human jejunum. Clin. Sci. (Lond.). 36:119-132. 